\title{
DẤU HIẾU LÂM SÀNG, HÌNH ẢNH MRI VÀ TỔN THƯO'NG TRONG MỔ CỦA RÁCH SỤN CHÊM KHỚP GỐI DO CHẤN THƯƠNG TẠI BỆNH VIỆN HỮU NGHI VIỆT ĐỨC
}

\section{TÓM TẮT}

Từ 7/2019 đến $5 / 2020$ chúng tôi đã tiến hành nghiên cứu trên 48 bệnh nhân rách sụn chêm khớp gối do chấn thương, được điều trị bằng phẫu thuật nội soi cắt tạo hình sụn chêm. Mục tiêu: Mô tả triệu chứng lâm sàng và hình ảnh cộng hưởng từ của rách sụn chêm do chấn thương tại Bệnh viện Hữu nghị Việt Đức. Phương pháp nghiển cứu: Thăm khám, ghi nhận các dấu hiệu lâm sàng và hình ảnh cộng hưởng từ của rách sụn chêm, đối chiếu dấu hiệu lâm sàng, hình ảnh tổn thương rách sụn chêm trên cộng hưởng từ với tổn thương trong mố. Kết quả: $100 \%$ có dấu hiệu đau khe khớp, 33,3\% có dấu hiệu kẹt khớp, dấu hiệu Mc Murray gặp $83,3 \%$, Appley $77,1 \%$ và Thessaly 47,9\%. 87,5\% trường hợp rách sụn chêm độ VI trên cộng hưởng từ, trong khi đó độ III chiếm 12,5\%. Kết luận: Đau khe khớp và kẹt khớp là những dấu hiệu chính khiến người bệnh đến khám bệnh. $100 \%$ bệnh nhân được chỉ định phẫu thuật bởi rách sụn chêm độ III và IV, trong đó đa số là độ IV.

Từ khoá: rách sụn chêm, phầu thuật nội soi

\section{SUMMARY}

EVALUATION OF CLINICAL SIGNS, MRI IMAGES, INTRAOPERATIVE INJURY OF

TRAUMATIC MENISCUS TEARS, WHICH HAVE ARTHROSCOPIC MENISCECTOMY AT VIET DUC HOSPITAL

From $7 / 2019$ to $5 / 2020$, we conducted a study on 48 patients with traumatic meniscus tears, have arthroscopic meniscectomy surgery. Objective: to evaluate clinical signs, MRI images of traumatic meniscus tears. Results: $100 \%$ showed signs of joint pain, 33.3\% showed signs of joint jam, Mc Murray's sign met $83.3 \%$, Appley $77.1 \%$ and Thessaly $47.9 \%$. $87.5 \%$ cases of meniscus tear at degree VI on magnetic resonance, while grade III accounts for $12.5 \%$. Conclusion: Joint pain and congestion are the main signs of medical attention. $100 \%$ of patients are indicated for surgery by grade III and IV meniscus tear, of which the majority is grade IV

Keywords: meniscus tears, arthroscopy, meniscectomy

\section{I. ĐẶT VẤN ĐỀ}

Sụn chêm có vai trò chính như các giảm xóc, hấp thu và truyền lực đều từ lồi câu xương đùi

\section{${ }^{1}$ Đai họ Y Hà Nọi}

2 Bệnh viên $Đ K$ Tỉnh Bắc Giang

Chịu trách nhiệm chính: Dương Đình Toàn

Email: Toanduongdinh@gmail.com

Ngày nhận bài: 19.2.2021

Ngày phản biên khoa hoc: 25.3.2021

Ngày duyệt bài: 2.4.2021

\section{Dương Đình Toàn ${ }^{1}$, Trần Phương Nam ${ }^{2}$}

xuống xương chày, làm giảm sang chấn sụn khớp. Thương tổn sụn chêm nếu không được chẩn đoán và điều trị kịp thời sẽ gây ra những hậu quả nghiêm trọng như đau, hạn chế chức nằng vận động khớp, thoái hóa khớp cũng như làm thương tổn thứ phát đến các thành phần khác của khớp ${ }^{1}$.

Việc xác định tổn thương sụn chêm dựa vào các nghiệm pháp thăm khám lâm sàng và chụp MRI khớp gối. Để đánh giá tần suất xuất hiện các triẹu chứng lâm sàng của rách sụn chêm khớp gối mức độ III, IV, cũng như dấu hiệu tổn thương trên phim cộng hưởng từ (MRI), chúng tôi tiến hành thực hiện nghiên cứu đề tài này.

\section{II. ĐỐI TƯỢNG VÀ PHƯƠNG PHÁP NGHIÊN CỨU}

48 bệnh nhân được chẩn đoán chấn thương khớp gối rách sụn chểm có chỉ định điều trị bằng phẫu thuật nôi soi cắt tạo hình sun chểm tại Bệnh viện Hữu Nghị Việt Đức từ tháng 7/2019 đến tháng 5/2020.

\subsection{Tiêu chuẩn lựa chọn}

- Bệnh nhân không phân biệt giới, tuổi, có tiền sử chấn thương được chẩn đoán rách sụn chêm với các triệu chứng lâm sàng như đau, kẹt khớp; dương tính với các nghiệm pháp McMurray, Appley...

- Trên phim chụp phim MRI có hình ảnh tổn thương sụn chêm độ III, IV

2.2. Tiêu chuẩn loại trừ

- Bênh nhân rách sụn chêm có thương tổn dây chẳng hoặc do thoái hoá

- Bệnh nhân không đồng ý tham gia nghiên cứu.

\subsection{Phương pháp nghiên cứu}

2.3.1. Thiết kế nghiên cứu: nghiên cứu mô tả cắt ngang tiến cứu

2.3.2. Địa điểm và thời gian nghiên cứu:

- Viện Chẩn thương chỉnh hình Bệnh viện Việt Đức.

- Thời gian nghiên cứu: từ tháng 7/2019 đến tháng $5 / 2020$

2.3.3. Cỡ mẫu: thuận tiện

2.3.4. Phương pháp thu thập số liệu:

- Lựa chọn bệnh nhân theo tiêu chuẩn lựa chọn.

- Thăm khám, thực hiện các nghiệm pháp lâm sàng đánh giá tổn thương sụn chêm.

- Đánh giá tổn thương sụn chêm trên phim MRI

- Đánh giá tổn thương sụn chêm trong mổ

- Ghi nhận kết quả, xử lý và phân tích số liệu. 
III. KẾT QUẢ NGHIÊN CỨU

\section{1. Đặc điểm chung đối tượng nghiên cứu}

\subsubsection{Giới}

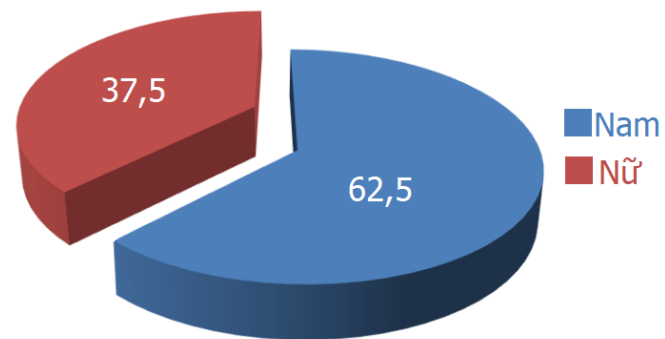

Biểu đồ 3.1. Phân bó bệh nhân theo giới tính

Nhận xét: Trong 48 bệnh nhân có 30 bệnh nhân là nam giới chiếm $62,5 \%$ và 18 bệnh nhân nữ giới chiếm 37,5\%. Tỷ lê bênh nhân nam cao hơn tỷ lệ bệnh nhân nữ 1,67 lần.

\subsubsection{Tuổi}

Bảng 3.1. Phân bố bệnh nhân theo tuổi

\begin{tabular}{|c|c|c|}
\hline Tuối & Số bệnh nhân & Tỷ lệ \% \\
\hline$<20$ & 7 & 14,6 \\
\hline $20-35$ & 23 & 47,9 \\
\hline $36-50$ & 12 & 25 \\
\hline$>50$ & 6 & 12,5 \\
\hline Tống số & $\mathbf{4 8}$ & $\mathbf{1 0 0}$ \\
\hline
\end{tabular}

Nhận xét: Nhóm tuối hay gặp tổn thương sụn chêm nhất là 20 - 35 tuổi chiếm 47,9\%. Nhóm tuổi ít gặp tổn thương sụn chêm nhất là trên 50 tuổi chiếm $12,5 \%$. Tuổi càng cao tỷ lê tổn thương sụn chêm càng giảm. Tuổi trẻ nhất là 14 , già nhất là 67. Tuổi trung bình là $35,2( \pm 12,8)$.

\subsubsection{Nguyên nhân chấn thương}

Bảng 3.2. Nguyên nhân chấn thương

\begin{tabular}{|c|c|c|}
\hline Nguyên nhân & Số bệnh nhân & Tỷ lệ \% \\
\hline Tai nạn giao thông & 11 & 22,9 \\
\hline Tai nạn thế thao & 25 & 52,1 \\
\hline Tai nạn sinh hoạt & 12 & 25 \\
\hline Tống số & $\mathbf{4 8}$ & $\mathbf{1 0 0}$ \\
\hline
\end{tabular}

Nhận xét: Nguyên nhân gây tổn thương sụn chêm hay gặp nhất là do tai nạn thể thao chiếm $52,1 \%$. Nguyên nhân do tai nạn giao thông chỉ chiếm $22,9 \%$. Tỷ lệ các nguyên nhân gây tổn thương sụn chêm là khác nhau với $p<0.05$

\subsubsection{Bên khớp gối bị tổn thương}

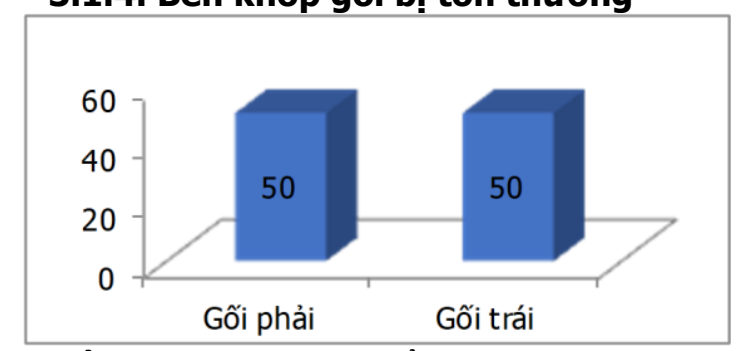

Biểu đồ 3.2. So sánh tổn thương khớp 2 bên
Nhận xét: Không có sự khác biệt giữa tỷ lệ tổn thương sụn chêm ở 2 bên khớp gối với $p$ > 0,05 . Không có bệnh nhân nào tổn thương sụn chêm ở cả hai khớp gối.

3.2. Đặc điểm lâm sàng và cận lâm sàng Bảng 3.3. Triệu chứng lâm sàng trước mố

\begin{tabular}{|c|c|c|}
\hline $\begin{array}{c}\text { Triệu chứng } \\
\text { lầm sàng }\end{array}$ & Số bệnh nhân & Tỷ lệ \% \\
\hline Đau & 48 & 100 \\
\hline Lục khục khớp & 35 & 72,9 \\
\hline Kẹt khớp & 16 & 33,3 \\
\hline Teo cơ & 9 & 18,8 \\
\hline Mc Murray & 40 & 83,3 \\
\hline Appley & 37 & 77,1 \\
\hline Thessaly & 23 & 47,9 \\
\hline
\end{tabular}

Nhận xét: Các dấu hiệu của tổn thương sun chêm với biểu hiện đau tại khe khớp chiểm $100 \%$, lục khục khớp 72,9\%, ket khớp 33,3\%, teo cơ $18,8 \%$. Thăm khám với nghiệm pháp McMurray dương tính 83,3\%, Appley dương tính $77,1 \%$, Thessaly dương tính $47,9 \%$.

Bảng 3.4. Kêt quả chụp MRI

\begin{tabular}{|c|c|c|c|}
\hline \multicolumn{2}{|c|}{ Triệu chứng } & $\mathbf{n}$ & $\%$ \\
\hline \multirow{3}{*}{$\begin{array}{c}\text { MRI sụn } \\
\text { chêm }\end{array}$} & Trong & 28 & 58,3 \\
\cline { 2 - 4 } & Ngoài & 18 & 37,5 \\
\cline { 2 - 4 } & Cá hai & 02 & 4,2 \\
\cline { 2 - 4 } & Tống & 48 & 100 \\
\hline
\end{tabular}

Nhận xét: Trong 48 bệnh nhân nghiên cứu, có 28 bệnh nhân có tổn thương sụn chêm trong chiếm $58,3 \%$. Chỉ gặp 2 bệnh nhân tổn thương cả hai sụn chêm chiếm 4,2\%. Tỉ lệ phân bố tổn thương sụn chêm trong cao hơn sụn chêm ngoài với $\mathrm{p}<0.05$.

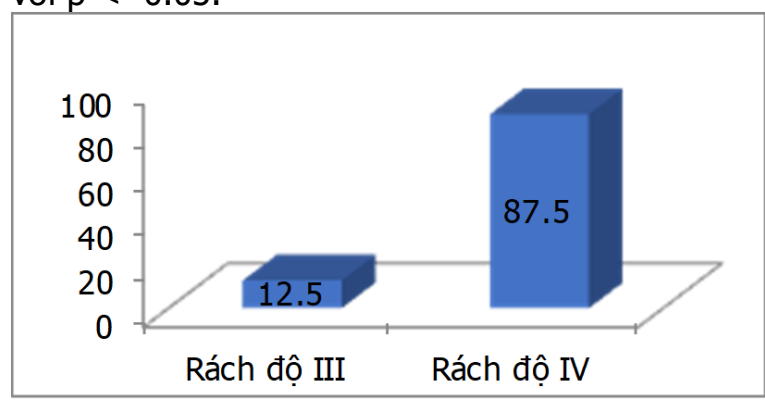

Biểu đồ 3.3. Phân bố mức đô tổn thương sưn chêm trên MRI

Nhận xét: Trong nhóm bệnh nhân nghiên cứu, tất cả các bênh nhân đều được chụp phim MRI, có $12,5 \%$ bệnh nhân tổn thướng sụn chêm độ III; $87,5 \%$ bệnh nhân tổn thương sụn chêm độ IV.

3.3. Đặc điểm tổn thương sụn chêm trong mô

3.3.1 Phân bố tân suât tổn thương theo sụn chêm 


\begin{tabular}{|c|c|c|}
\hline Sụn chêm tổn thương & $\begin{array}{l}\text { Số bệnhh } \\
\text { nhẩn }\end{array}$ & $\begin{array}{l}\text { Tỷ lệ } \\
\text { \% }\end{array}$ \\
\hline Sụn & 28 & 58,3 \\
\hline Sụn chêm ngoài & 18 & 37,5 \\
\hline
\end{tabular}

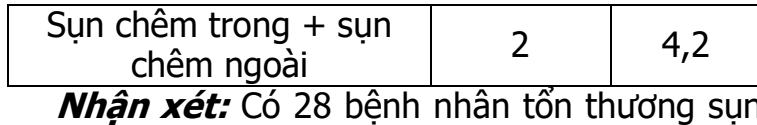
chêm trong chiếm $58,3 \%$ và 18 bệnh nhân tổn thương sụn chêm ngoài chiếm $37,5 \%$.

3.3.2. Tân suất tổn thương sựn chêm rách theo vị trí

Bảng 3.6. Tần suât tổn thương sụn chêm rách theo vị trí

\begin{tabular}{|c|c|c|c|c|c|c|}
\hline \multirow{3}{*}{ Vị trí } & \multicolumn{4}{|c|}{ Sụn chêm } & \multirow{2}{*}{\multicolumn{2}{|c|}{ Tổng số }} \\
\hline & \multicolumn{2}{|c|}{ SC trong } & \multicolumn{2}{|c|}{ SC ngoài } & & \\
\hline & $\mathbf{n}$ & $\%$ & $\mathbf{n}$ & $\%$ & $\mathbf{n}$ & $\%$ \\
\hline Sừng trước & 5 & 16,7 & 2 & 10 & 7 & 14 \\
\hline Thân SC & 7 & 23,3 & 6 & 30 & 13 & 26 \\
\hline Sừng sau & 14 & 46,7 & 9 & 45 & 23 & 46 \\
\hline Sừng trước và thân & 1 & 3,3 & 1 & 5 & 2 & 4 \\
\hline Sừng sau và thân & 3 & 10 & 2 & 10 & 5 & 10 \\
\hline Tống số & 30 & 100 & 20 & 100 & 50 & 100 \\
\hline
\end{tabular}

Nhận xét: Trong nghiên cứu của chúng tôi có 2 bênh nhân rách cả 2 sụn chêm nên tổng số sụn chêm được đánh giá là 50 . Tỷ lệ rách sừng sau sụn chêm trong và sụn chểm ngoài chiếm tỷ lệ cao nhất lần lượt là $46,7 \%$ và $45 \%$. Tỷ lệ rách sừng trước sụn chêm trong và sụn chêm ngoài đêu thấp hơn các nhóm khác.

Tỷ lệ tổn thương cả 2 sừng sụn chêm thấp, chủ yếu là rách kiểu quai xô.

\subsubsection{Hình thái tổn thương giải phẫu bệnh}

Bảng 3.7. Hình thái tổn thương sun chểm trong nôi soi theo O"Connor

\begin{tabular}{|c|c|c|c|c|c|c|}
\hline $\begin{array}{c}\text { Hình thái } \\
\text { tổn thương }\end{array}$ & \multicolumn{2}{|c|}{ Sụn chểm trong } & \multicolumn{2}{c|}{ Sụn chêm ngoài } & \multicolumn{2}{c|}{ Tống số } \\
\cline { 2 - 7 } & $\mathbf{n}$ & $\mathbf{\%}$ & $\mathbf{n}$ & $\mathbf{\%}$ & $\mathbf{N}$ & $\mathbf{\%}$ \\
\hline Rách dọc & 13 & 43,3 & 8 & 40 & 21 & 42 \\
\hline Rách ngang & 6 & 20 & 3 & 15 & 9 & 18 \\
\hline Rách chéo & 8 & 26,7 & 3 & 15 & 11 & 22 \\
\hline Rách nan quạt & 1 & 3,3 & 4 & 20 & 5 & 10 \\
\hline Rách biến dạng & 2 & 6,7 & 2 & 10 & 4 & 8 \\
\hline Tống số & $\mathbf{3 0}$ & $\mathbf{1 0 0}$ & $\mathbf{2 0}$ & $\mathbf{1 0 0}$ & $\mathbf{5 0}$ & $\mathbf{1 0 0}$ \\
\hline
\end{tabular}

Nhận xét: Tỷ lệ rách dọc chiếm 42\%, rách ngang chiếm $18 \%$, rách chéo $22 \%$, rách nan quạt chiếm $10 \%$, rách biến dạng chiếm $8 \%$.

\section{BÀN LUÂN}

4.1. Đặc điểm lâm sang. Bệnh nhân đến với chúng tôi thường biểu hiện lâm sàng phổ biến như: Đau tại khe khớp, lục khục trong khớp, kẹt khớp, teo cơ tứ đầu đùi, nghiệm pháp McMurray, Apley, Thessaly dương tính..., các triệu chứng này ở mỗi bệnh nhân biểu hiện mức độ khác nhau, có BN chỉ đau khe khớp đơn thuần, có $B N$ đau khe khớp và dấu hiệu kẹt khớp. Trong nhóm nghiên cứu có $100 \%$ phàn nàn về dấu hiệu đau khe khớp khi vận động và biểu hiện rõ khi thăm khám. Cùng quan điểm của Nguyễn Quốc Dũng ${ }^{2}$ nhưng cao hơn của tác giả RusselU.A tỷ lệ đau khe khớp là $93 \%{ }^{3}$. Dấu hiệu lục khục trong khớp gối gặp ở 72,9\% trường hợp, dấu hiệu này theo nghiên cứu của Trương Chí Hữu $75 \%{ }^{4}$, Nguyễn Quốc Dũng $87.7 \%{ }^{5}$ và Trương Kim Hùng $71.6 \%{ }^{6}$. Dấu hiệu teo cơ tứ đầu đùi chúng tôi gặp $18,8 \%$. Ba triệu chứng trên có thể gặp trong các bệnh lý khớp gối khác như thoái hóa, đứt dây chằng chéo, ảnh hưởng lâu dài gây giảm chức năng vận động cơ đùi chứ không phải là dấu hiệu đặc trưng của thương tổn SC. Nhưng nó có giá trị gợi ý cho chúng ta nghĩ đến thương tổn thành phàn khớp gối. Dấu hiệu kẹt khớp gặp trong 33,3\% các trường hợp, đặc biệt đối với các trường hợp ket khớp thường xuyên gây hạn chế gấp hoặc duỗi gối khi phẫu thuật thường thất rách sụn chêm kiểu quai xô.

Để chẩn đoán những tổn thương bên trong khớp, không chỉ dựa vào triệu chứng lâm sàng. ở khớp gối, mỗi tổn thương đều có những dấu hiệu đặc thù. Để chẩn đoán rách sụn chêm có ba nghiệm pháp: McMurray, Appley và Thessaly được áp dụng. Theo các tác giả mỗi nghiệm pháp có tỉ lệ chẩn đoán xác định khác nhau, có trương hợp dương tính với nghiệm pháp này nhưng lại âm tính khi sử dụng nghiềm pháp khác và ngược lại. Tuy nhiên theo Nguyễn Quốc Dũng 
100\% trường hợp đều có tối thiểu một nghiệm pháp dương tính ${ }^{5}$.

Chính vì vậy việc thăm khám lâm sàng một khớp gối đòi hỏi phải được thực hiện một cách tỷ mỷ, chính xác để để có được chẩn đoán đúng đắn.

Tỷ lệ dương tính của các nghiệm pháp McMurray, Appley, Thessaly lần lượt là $83.3 \%$, $77,1 \%, 47,9 \%$. So sánh với một số tác giá như của Trương Chí Hữu là $100 \%$, $76 \%$ và $58 \%$, của tác giả Steinbrueck K., Wiehmann J.c lần lượt là $35 \%, 46 \%$ và $42 \%$. Chúng tôi cho rằng sự khác biêt này không có ý nghĩa, vì sự thành thục của mỗi bác sĩ khám lâm sàng là hoàn toàn khác nhau.

4.2. Đặc điểm cận lâm sang. Bên cạnh việc thăm khám lâm sàng, ngày nay chụp cộng hưởng từ khớp gối cho phép chẩn đoán chính xác thương tổn sụn chêm với tỷ lệ cao. Các tác giả đều có chung nhận xét là nếu thực hiện đúng MRI có độ nhạy và độ đặc hiệu cao đến $90 \%$ trong phát hiện tổn thương tại sụn chêm trong. Với sụn chêm ngoài, MRI cho độ chính xác và độ nhạy thấp hơn với độ nhạy $80 \%$ và độ đặc hiệu $90 \%{ }^{9}$.

Trong nghiên cứu chúng tôi tiến hành chụp MRI khớp gối đánh giá thương tổn trên toàn bộ 48 bệnh nhân, trong đó có 28 bệnh nhân rách sụn chêm trong, 18 bệnh nhân rách sụn chêm ngoài, chỉ có 2 bệnh nhân rách cả 2 sụn chêm. Số bệnh nhân rách sụn chêm độ III trên phim chụp MRI theo Quinn chiếm 12,5\%, rách độ IV chiếm $87,5 \%$.

Như vậy để chẩn đoán một bệnh nhân có tổn thương sụn chêm bên cạnh các triệu chứng cơ năng khiển cho bệnh nhẩn phải đến viện khám, chúng ta phải kết hợp thăm khám lâm sàng một cách thật tỷ mỷ, chính xác, đầy đủ các nghiệm pháp và dựa trên kết quả chụp MRI. Tuy nhiên trong một số trường hợp bệnh nhân có triệu chứng cở năng không rõ ràng, thăm khám lâm sàng đầy đủ các nghiệm pháp không dương tính rõ, kết quả chụp MRI cũng cho kết quả không nhìn thây tổn thương, khi đó việc quyết định cho bệnh nhân nội soi khớp vẫn cần được đặt ra để làm chẩn đoán và điều trị.

4.3. Sưn chêm tổn thương. Nghiên cứu của nhiều tác giả cho thấy sụn chêm trong có tỷ lệ tổn thương cao hơn sụn chêm ngoài. Northmore-Ball nghiên cứu 99 trường hợp tổn thương sụn chêm thấy tỷ lệ sụn chêm trong là $71 \%$ và sụn chêm ngoài là $29 \%$. Tương tự như vậy Stein T. nhận thấy trong nhóm nghiên cứu 204 sụn chêm bị tổn thương do nguyên nhân chấn thương có 136 sụn chêm trong(66.7\%) và 68 sụn chêm ngoài. Kết quả nghiên cứu của
Metcalf $M$. cho thấy sự khác biệt về tỷ lệ tổn thương sụn chêm trong so với sụn chêm ngoài ở tưng lứa tuổi. Với lứa tuổi dưới 40 tỷ lệ tổn thương sun chêm trong so với sụn chêm ngoài là $62 \%$ và $38 \%$ trong khi ở lứa tuổi trên 40 tỷ lệ này là $78 \%$ và $22 \%$. Tác giả cho rằng sự khác biệt này là do hiện tượng biến dang trục chi mở góc vào trong ở những bệnh nhẩn lớn tuổi, làm cho sụn chêm trong chịu tác động nhiêu hơn từ trọng lượng cớ thể.

Trong nghiên cứu của chúng tôi, sự phân bố tỷ lệ tổn thương sụn chêm trong là $58,3 \%$, tổn thướng sụn chêm ngoài là $37,5 \%$, cả 2 sụn chêm là $4,2 \%$. Nghiên cứu của chúng tôi phù hợp với nghiên cứu của nhiều tác giả trong nước như Phạm Chí Lăng khi nghiên cứu 94 trường hợp rách sụn chêm khớp gối cho thấy tỷ lệ sụn chêm ngoài là 55 trường hợp $(58.5 \%)$ và sụn chêm ngoài là 30 trường hợp $(41.5 \%)^{4}$. Cũng như vậy tỳ lệ tổn thương sụn chêm trong so với sụn chêm ngoài theo Trương Chí Hữu là $48.2 \%$ và $51.3 \%{ }^{8}$. Tác giả Nguyễn Quốc Dũng thì cho tỷ lệ tổn thương sụn chêm trong và sụn chêm ngoài là $52.7 \%$ và $47.3 \% 5$.

Nhìn chung, công trình nghiên cứu của các tác giả nước ngoài đều thống nhất tỷ lệ sụn chêm trong bị tổn thương cao hơn so với sụn chêm ngoài. Giải thích cho hiện tượng này, các tác giả cho rằng do sụn chêm trong phải chịu tác động của trọng lực cơ thể cao hơn. Sụn chêm trong chịu tác động $70 \%$ trọng lượng cơ thể trong khi phần tác động lên sưn chêm ngoài chỉ là $50 \%$. Về đặc điểm giải phấu, khả năng di chuyển của sun chêm trong kém hơn so với sụn chêm ngoài dẫn đến nguy cơ tổn thương cao.

4.4. Hình thái tổn thương sụn chêm. Trong nghiên cứu của chúng tôi tỉ lể rách dọc chiếm $42 \%$, rách ngang chiếm $18 \%$, rách chéo $22 \%$, rách nan quạt chiếm $10 \%$, rách biến dạng chiếm $8 \%$. Kết quả này tương tự như nghiên cứu của Nguyến Quốc Dũng trên 478 bệnh nhân rách sụn chêm cho kết quả $46.8 \%$ bệnh nhân có kiểu rách dọc ${ }^{5}$, hay Trương Kim Hùng có tỷ lệ $59.2 \%$ bệnh nhân rách sụn chêm kiểu rách dọc. Warren R.D mô tả hình thái tổn thương trên 267 sụn chêm cho tỷ lệ rách dọc chiếm $42 \%$, tiếp đó là rách hình vạt với $18,7 \%$. Ferkel R.D trong nghiên cứu 142 trường hợp thương tổn sun chêm, rách dọc chiếm $50,7 \%$, hình vạt đứng thứ 2 với $18,31 \%$.

Nhóm đối tượng nghiên cứu của chúng tôi chủ yếu là những người trẻ, mặt sụn khớp dày, đàn hồi, hấp thu lực tốt nên thường thấy rách dọc, ngoài ra do có sự sắp xếp khác nhau của 
các bó sợi collagen ở trong các vị trí khác nhau của sụn chêm nên dẫn đến các hình thái tổn thương giải phẫu bệnh khác nhau tổn thương ở phần rìa sụn chêm sát bao khớp thường là đường rách dọc, tổn thương tại phân tự do thường là tổn thương rách ngang hoặc rách hình vạt. Người lớn trên 30 tuổi chất lượng sụn bắt đầu suy giảm, không hấp thu được các lực xoay nên cho ra hình dạng rách ngang hoắc rách chéo. Người già sụn khớp thoái hóa nhiêu, lớp sụn mất đi, khe khớp gối hẹp lại, cử động lăn của lồi cầu trên mâm chày bị ma sát nhiều, nên thường có rách nham nhở.

\section{KẾT LUÂ̂N}

- Tuổi hay gặp < 35 tuổi chiếm 62.5\%.

- Nguyên nhân chấn thương thể thao 25 BN chiếm $52,1 \%$

- Nam / Nũ = 5/3.

- Triệu chứng đau gặp ở 100\% bệnh nhân, kẹt khớp gặp 33,3\%, teo cơ gặp 18,8\%.

- Tỳ lệ rách sụn chêm độ III trên MRI là $12,5 \%$, độ IV là $87,5 \%$.

- Tý lệ rách sụn chêm trong đơn thuần chiếm $58,3 \%$, sụn chêm ngoài đơn thuần chiếm $37,5 \%$.

- Tỷ lệ rách sừng sau sụn chêm trong và ngoài chiếm cao nhất lần lượt là $46,7 \%$ và $45 \%$.

- Hình thái tổn thương sụn chêm chủ yêu là loại rách dọc chiếm $42 \%$.

\section{TÀI LIẸU THAM KHẢO}

1. AHen F. Anderson, Robert B. Snyder, and A. Brant Lipscomb (2001). Anterior Cruciate
Ligament Reconstruction: A Prospective Randomized Study of Three Surgical Methods. The American Journal of Sports Medicine; Vol.29, No.3: 272-279.

2. Trịnh Đức Thọ, Phạm Ngọc Nhữ (2003). Nhân xét điêu trị tổn thương sụn chêm khớp gối qua 35 trường hợp phẫu thuật nội soi. Y học Việt Nam số đặc biệt; 296-299.

3. Russell J.A Tregonning (1983). Closed partial Meniscectomy early results for simple tears /vith mechanical symptoms. J Bone Joint Surg,1983; 65B: 378-382.

4. Pham Chí Lăng, Nguyễn Văn Quang, Trương Chí Hữu (2000). Phẫu thuât cắt môt phân sun chêm qua nội soi trong điều trị rách sụn chêm khớp gối do chấn thương. Tạp chí Y hoc TP HCM, chuyên đề $\mathrm{CTCH}$, 2000; Số 4, tâp 4, 222-227.

5. Nguyê̂n Quốc Dũng (2012). Nghiên cứu hình thái tổn thương sụn chễm khớp gối và đánh giá kết quả điều trị bằng phẩu thuật nội soi. Luận văn tiến sỹ y hoc.

6. Trương Kím Hùng (2009). Đánh giá kết quả nội soi khớp gối trong chẩn đoán và điểu trị rách sụn chêm do chấn thương tại bệnh viện TWQĐ 108. Luận văn thạc sỹ y học.

7. Mandelbaum B.Ret al (1986). Magnetic résonance imaging as a tool for evaluation of traumatic knee injuries. Anatomical and pathoanatomical correlations.Amer J Sports Med; Vol 14, 361-370.

8. Trương Trí Hữu (2003). Đánh giá kết quả điều trị rách sụn chêm do chân thương thể thao khớp gối bằng phương pháp phẫu thuật nội soi. Luận án chuyên khoa cấp II, Đại Học Y Dược TPHCM.

9. Nguyển Tuấn Anh (2014). Phân tích đặc điểm hình ảnh và giá trị chẩn đoán của công hưởng từ trong tổn thương sụn chêm gối do chấn thương. Luận văn thạc sỹ, Trường Đại học Y Hà Nội.

\title{
ĐÁNH GIÁ KẾT QUẢ BƯớC ĐẦU ĐIỀU TRI GÃY CỔ XƯƠ'NG ĐÙI Ở BÊ̂NH NHÂN TRÊN 80 TUỔI BẰNG PHẪU THUÂ̂T THAY KHỚP HÁNG BÁN PHẦN KHÔNG XI MĂNG
}

\author{
Vũ Văn Khoa*, Nguyễn Mạnh Khánh**, Nguyễn Ngọc Hân*** \\ TÓM TẮT. \\ Mục tiêu: Đánh giá kết quả phẫu thuật thay khớp \\ háng bán phần không xi măng điều trị gã̃y cổ xương \\ đùi ở bệnh nhân trên 80 tuổi. Đối tượng và phương \\ pháp nghiên cứu: 55 bệnh nhân trên 80 tuổi được

\footnotetext{
*BV Việt Đức

**Viện CTCH - BV Việt Đức

***Bंv Nhiệt đới trung ương

Chịu trách nhiệm chính: Vũ Văn Khoa

Email: drvuvankhoa@gmail.com

Ngày nhận bài: 23.2.2021

Ngày phản biên khoa học: 29.3.2021

Ngày duyệt bài: 2.4.2021
} \\ phẫu thuật thay khớp háng bán phần không xi măng \\ tại Bệnh viện Hữu Nghị Việt Đức từ năm 2017-2019. \\ Kết quả nghiên cứu: Tuổi trung bình 86,5( 80-102 \\ tuổi), tỷ lê nam/nữ là $0,06 / 1$ (3 nam và 52 nữ). Khớp \\ háng bị tổn thương: phải $43,6 \%$, trái $56,4 \%$. Kết quả \\ theo thang điểm Harris: tốt và rất tốt $90,9 \%$, khá \\ $5,5 \%$, kém 3,6\%. Trong nghiên cứu này chúng tôi ghi \\ nhân có 1 trường hợp nhiễm khuẩn vết mô, không \\ gặp tai biến do gây tề, gây mê, viêm phổi, tắc mạch, \\ loét tỳ đè hay tử vong. Kết luân: Thay khớp háng \\ bán phần không xi măng ở bệnh nhân trên 80 tuổi \\ gãy cổ xương đùi cho kết quả khả quan. Bệnh nhân \\ vận động được sớm, hạn chế được các biến chứng. \\ Tì̛ khóa: Thay khớp háng bán phân không xi \\ măng, gãy cổ xương đùi, bệnh nhân trên 80 tuổi.
}

